\title{
1 Assessing non-intended effects of farming practices on field margin \\ 2 vegetation with a functional approach
}

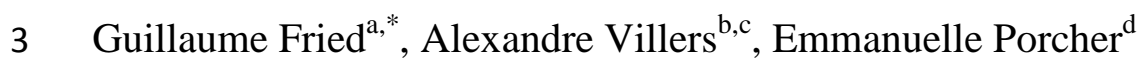

aAnses, Laboratoire de la Santé des Végétaux, Unité Entomologie et Plantes invasives, 755 avenue du campus Agropolis, CS30016, 34988 Montferrier-sur-Lez cedex, France,

$7 \quad$ guillaume.fried@anses.fr

${ }^{\mathrm{b}}$ Unité de recherché Biostatistique et processus spatiaux, INRA, Domaine Saint-Paul, Site Agroparc, 84914 Avignon Cedex 9, France, villers.alexandre@gmail.com

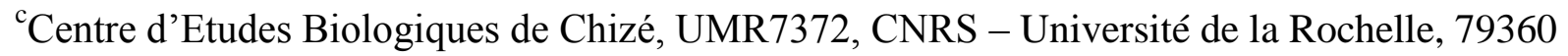

Villiers-en-Bois, France

${ }^{\mathrm{d}}$ Centre d'Ecologie et des Sciences de la Conservation (CESCO), Muséum national d'Histoire naturelle, Centre National de la Recherche Scientifique, Sorbonne-Université, 61 rue Buffon, 75005 Paris, France, emmanuelle.porcher@mnhn.fr

*Corresponding author

Anses, Laboratoire de la Santé des Végétaux, Unité Entomologie et Plantes invasives, 755

Fax: +33(0)467020070 
To assess the unwanted side effects of farming practices on non-target plants, we used a nationwide survey of the vegetation of arable field margin strips. The vegetation was surveyed during two years $(2013,2014)$ in 430 field margins distributed over all agricultural regions of France. We used two complementary multivariate, trait-based approaches to examine how ten plant traits were related to ten environmental variables describing abiotic conditions, landscape factors, field margin management and in-field practices. Generalized additive mixed models were also developed to assess how the same environmental variables correlated with species richness, functional diversity and relative richness of agrotolerant versus hemerophobic species. Traits responded primarily to an environmental gradient of landscape diversity and field margin management. For instance, narrow field margin strips, frequent management and presence of a ditch favoured annual plants, small size at maturity and perennial plants, respectively. The second environmental gradient affecting plant traits was related to field size and intensity of in-field farming practices. On this gradient, fertilizer drift appeared to have a much stronger effect on plant trait composition of field margin strips than herbicide drift. The relationship between species richness, or functional diversity, and environment was consistent with the trait-based approach: the two former variables were negatively correlated with agriculture intensification (e.g. field size). However, this analysis also highlighted new covariates, such as a negative relationship between frequency of herbicide use and species richness. Some of the observed patterns seemed to be driven by differential responses of agrotolerant versus hemerophobic species, with the latter being more species-rich under organic than under conventional farming. Despite efforts to reduce nitrogen inputs since the 2000s, our results shows that $\mathrm{N}$-fertilization still has significant nonintended effects on field margin vegetation. More generally, increasing the width of field margin strips, keeping or restoring semi-natural elements (ditches, hedges) in the field 
48 boundary, and lowering the number of management events may promote grassland plant 49 species more typical of semi-natural habitats.

50 Keywords: Agrotolerant species ; Field margin width ; Agricultural land use intensity;

$51 \quad$ Nitrogen fertilizer ; Pesticide drift; Plant diversity

52

53

54 


\section{Introduction}

During the second half of the twentieth century, the conjunction of mechanization, landscape simplification and widespread use of chemical inputs has resulted in dramatic changes in the environmental conditions of arable landscapes (Stoate et al., 2001). This is associated with both a loss of non-crop habitats (Robinson and Sutherland, 2002) and a massive decline in abundance and diversity of biotas associated with arable fields (Benton et al., 2002; Donald et al. 2001; Fried et al., 2009). In many agricultural landscapes, field boundaries have become the last remnants of semi-natural habitats and their functional role as refugia for a high level of botanical diversity and for supporting a diverse fauna has been increasingly recognized (Marshall and Moonen, 2002). However, the quality of this habitat may also be lowered by intensive agriculture, particularly due to leaked or misplaced fertilisers and herbicides in the adjacent arable land (Boutin and Jobin, 1998; de Snoo and van der Poll, 1999; Kleinj and Verbeek, 2000). Assessing the effects of farming practices on non-target organisms is crucial to guide farmers towards better practices, and also as a part of official post registration monitoring of pesticides. However, detecting such effects requires disentangling the role of agricultural practices, landscape and local abiotic environmental conditions (e.g. soil type).

Previous studies have shown that the vegetation of field boundaries is influenced by the combination of both environmental conditions and management practices. Several studies found that the plant community composition of field boundaries varies primarily with landscape structure (proportion and diversity of non-arable habitat patches at the landscape level) and spatial variables (Aavik et al., 2008; Aavik and Liira, 2010; Tarmi et al., 2009). Local habitat structure (boundary width, presence of ditches and hedgerows) and boundary management were also shown to be important factors, while the influence of farming in the adjacent field was less clear (Tarmi et al., 2009). Conversely, Bassa et al. (2011) found significant differences between broad management type (organic versus conventional), with 
fewer effects of landscape structure. Similarly, Petersen et al. (2006) highlighted a rapid effect of conversion to organic farming in field boundaries of dairy farms, with fewer nitrogendemanding or ruderal species and more stress-tolerant species. Kleijn and Verbeek (2000) also found a strong effect of in-field fertilisation on species richness of the boundary vegetation, while boundary management and use of herbicides in the boundary had no effects. Comparing unsprayed and sprayed ditches, de Snoo and van der Poll (1999) found a significant effect of herbicide drift only on dicotyledonous species of adjacent winter wheat field boundaries. Some of these previous results, and a vast literature in plant ecology (reviewed e.g. in Garnier and Navas 2012), suggest that the impacts of both agricultural practices and the landscape on the community composition of field margins depend on some key functional traits, particularly response traits sensu Lavorel and Garnier (2002). Therefore, the use of trait-based approaches may offer opportunities for a deeper mechanistic understanding of the impacts of environmental factors, including management practices, on the vegetation of field margins.

Despite the growing number of studies, there have been few attempts so far to characterize the composition of plant functional traits in field margin communities, and its environmental correlates (but see Alignier and Baudry, 2015; Alignier, 2018; Chaudron et al., 2018). Here we use trait-based approaches to examine which environmental variables best explain the assembly of field margin plant communities, using a nationwide standardized monitoring scheme designed to detect the non-intended effects of in-field practices, particularly the use of synthetic inputs, on biodiversity. The following questions were addressed: (1) Are the links between environmental conditions, in-field management practices and plant traits in field margins consistent with expectations derived from ecological knowledge in more natural settings (see below for the details of such expectations)? (2) Are there any trait syndromes associated with gradients of management practices and/or land-use 
intensity? (3) What factors influence plant species richness and plant functional diversity in field margins?

\section{Methods}

\subsection{Vegetation survey}

The "500 ENI" network is a long-term survey initiated by the French Ministry of Agriculture. It is designed to detect and document nationally any significant changes in wild flora and fauna (birds, beetles, and earthworms) of agricultural landscapes that could be associated with non-intended effects of agricultural practices, especially fertilization and pesticides (Andrade et al., in prep.). For this purpose, 500 fields distributed over all agricultural regions of France (including Corsica) were chosen to be representative of the main crop productions, using a stratified sampling within each administrative region. The survey focuses on three types of production systems: annual crops (wheat or maize as the main crop production), vineyards and market gardening centred on lettuce production. Here, we worked with a subset of 430 field margins (out of 500), chosen as those for which comprehensive floristic data were available in both 2013 and 2014 (see Figure 1 for a distribution map).

Three main areas are recognized in field margins (Greaves \& Marshall, 1987; Marshall \& Moonen, 2002): crop edge, field margin strip and field boundary. The area surveyed in the "500-ENI" program excludes the crop edge (sometimes called conservation headland) which is located in the first 1-6 meters within the crop. It also excludes the cultivated strip, outside the last row of crop, which is an area with mostly bare soil usually colonized by weed species from the field. The area of interest is the field margin strip (sensu Marshall \& Moonen, 2002, hereafter field margin), which is the uncultivated herbaceous vegetation area between the cultivated strip and another patch in the landscape. The latter can be a field boundary 
embodied by a ditch and/or a hedge, or other land covers such as a road, a track, other fields or grassland-type vegetation (see below).

Wild plant species were identified in ten $1 \mathrm{~m}^{2}$ quadrats located in the field margin. The ten quadrats were divided into two sets of five contiguous quadrats of $0.25 * 2 \mathrm{~m}^{2}$ separated by 30 m. The quadrats were placed in the centre of the field margin (i.e. equidistant from the field and the adjacent land cover). Their position was maintained in the same field margin across the two years but their exact location may slightly differ from year to year. Only presenceabsence of plant species was recorded in the ten quadrats, so that the abundance of each species was characterized by a frequency of occurrence (0-10) in each field margin. Surveys were performed at the peak of flowering, which is from late April to early August depending on locations ( $50 \%$ of the observations were made between June $6^{\text {th }}$ and July $\left.11^{\text {th }}\right)$. In order to avoid the issue of differences in rare species detection among observers, and because trait data are not available for all species, we focused on species observed in more than $1 \%$ of the surveyed margins, i.e. 186 of 331 species observed in total, representing $94.9 \%$ of the total abundance (number of quadrats). All subsequent analyses were performed on this subset of species.

\subsection{Environmental data}

Ten environmental variables were used to describe the field margins and were grouped into four categories: 1) two abiotic factors, 2) three landscape factors, 3) two field margin management practices and 4) three management practices within the adjacent field. (1) From the coordinates of the field margin, we retrieved eight factors from the Soilgrids dataset at 250m resolution (Hengl et al., 2017). We performed a PCA and extracted the first two axes, which represented $65 \%$ of total inertia. Axis 1 was associated with a combination of soil $\mathrm{pH}$ 
and texture, opposing sandy acidic soils (positive values) to basic clay soils (negative values). Axis 2 was positively associated with the level of organic matter (see Appendix A for the detailed outputs of the PCA). (2) Landscape composition was described on the basis of the proportion of land cover (crop, grassland, woodland, etc.) within $250 \mathrm{~m}$ of the field margin. By summing the proportion of all non-cropped area (i.e. permanent grasslands, heaths, hedges and woodland as well as water surfaces), we characterized the amount of non-arable land cover, which is a well-established landscape metric for landscape complexity (Gabriel et al., 2005). The size of the field adjacent to the studied margin was also considered as a landscape variable. The local habitat structure immediately adjacent to the field margin (i.e. the field boundary sensu Marshall \& Moonen, 2002) was characterized by the presence/absence of ditches or hedges resulting in four field boundary classes: i) ditch and hedge present, ii) ditch present, iii) hedge present, iv) no ditch or hedge. This latter category corresponds to field boundaries with no particular features, where the field margin is contiguous with another land cover type, such as roads or tracks (68\%), other fields (12\%), or grassland-type vegetation (16\%). (3) Field margin management was characterized by the number of management events; mowing was the dominant management type ( $n=582$ occurrences for the two years) with only few margins with use of chemicals $(n=8)$ or grazing $(n=12)$. Field margin width was also recorded. When the surveyed arable field was adjacent to a grassland, field margin width was measured up to the visible boundaries of cadastral parcels. (4) Management within the field was summarized by the amount of nitrogen fertilizer input, and the Treatment Frequency Index (TFI) for herbicides and insecticides. TFI is calculated as the cumulative ratio of the dose applied to the recommended dose, for all treatments applied during the growing season (Halberg, 1999). Finally, observation date (number of days since January $1^{\text {st }}$ ) and year (2013 or 2014) were also added as explanatory variables. The farming system (conventional versus organic) in the field adjacent to the surveyed margin was also incorporated in the analyses 
either as a supplementary variable (when in-field practices were already included) or as a primary variable accounting for management practices.

\subsection{Plant trait data}

Seven functional traits and three indicators of ecological performance were chosen on the basis of hypotheses related to potential non-intentional effects of farming practices and field margin management on two main ecological axes, namely fertility (resources) and disturbances (Table 1). The level of disturbances (frequency and intensity) is assumed to favour short-lived species reaching small height at maturity but having rapid growth rate and high seed output (ruderal strategy, e.g. Lavorel and Garnier 2002, Grime 2006). Thus, disturbances such as the number of management events in the margins and herbicide drift related to the intensity of herbicide use are expected to promote a higher proportion of annual species, species with high Specific Leaf Area (SLA), low seed mass and short plant height. The level of fertility is assumed to favour nitrophilous species, i.e. with high Ellenberg-N, tall competitive plants or rapid growing species with high SLA values (e.g. Lavorel and Garnier 2002, Grime 2006), although trait responses to these two major environmental drivers can sometimes be more complex (Douma et al. 2012). Additional hypotheses were also considered. The presence of hedges can favour shade-tolerant species (low Ellenberg-L values), while the presence of ditches can favour water-demanding species (high Ellenberg-H values). Disturbance caused by insecticides are expected to favour selfing species and species with abiotic pollination over entomogamous species, via a decrease in the abundance and diversity of pollinators (Brittain and Potts 2011). Landscape diversity and proximity of seminatural habitats are expected to benefit plants with animal pollination and dispersal (e.g.

Steffan-Dewenter and Tscharntke 1999). A functional diversity index can be computed on the 
basis of these traits (see below) in addition to classical taxonomic diversity indices such as species richness. Since we have included both response and effect traits (Lavorel and Garnier, 2002), a field margin with high functional diversity can be interpreted as supporting: i) a community including species with different ecological strategies ensuring more resistance to environmental changes and, ii) a community including species with different functions providing a larger range of resources for species of higher trophic levels.

In parallel to classic plant traits, we also used an emergent classification of species on the basis of their responses to agricultural disturbances. Following Aavik and Liira (2009), species were classified into agrotolerant (i.e. species adapted to current disturbance regimes in arable fields, under modern conventional agriculture) and hemerophobic species (i.e., species that are sensitive to soil tillage and/or herbicides). Each species was classified on the basis of its frequency of occurrence in arable fields using data of the Biovigilance Flore network (2002-2012), which covered the same area as in the present survey, i.e. the whole of France (Fried et al., 2008). The 47 species present in more than $10 \%$ of the 1440 arable fields surveyed in Biovigilance Flore were considered as agrotolerant, while the hemerophobic group was made of both grassland species and rare arable weeds that are not adapted to current farming practices (see Appendix B).

\subsection{Data analysis}

To analyse the relationships between the variation in plant traits of field margins and the variation in environmental factors, we followed the framework introduced by Dray et al. (2014) combining the RLQ multivariate technique (an ordination analysis) and the fourth corner analysis (a hypothesis testing analysis). RLQ assigns scores to species, samples, traits, and environmental variables along orthogonal axes and yields a graphical summary of the main structures (Dolédec et al., 1996), while the fourth corner analysis tests the multiple 
associations between one trait and one environmental variable at a time (Dray and Legendre, 2008).

Both methods use three tables: the R-table, which consists of the 860 samples (430 field margins $\mathrm{x}$ two years) described by the ten environmental and two temporal variables, the Q-table containing the 186 species described by their 10 traits and the L-table describing the floristic composition of the 860 samples via the abundance of 186 species. The L-table therefore links the R- and the Q-tables. For the RLQ analysis, a correspondence analysis (CA) was first performed on the L-table using the raw frequency of occurrence score for each species (0-10). Next, a Hill and Smith analysis (a mixed ordination method similar to PCA that allows combining quantitative variables and factors; Hill and Smith, 1976) was performed on the R-table (using the row scores of the CA on the L-table as canonical factor), and on the Q-table (using the column scores of the CA on the L-table as canonical factor). Finally, RLQ calculates two separate co-inertia analyses on the R-L and L-Q tables. RLQ selects the axes that maximise the co-variance between the site scores constrained by the environmental variables (the R-table) and the species scores constrained by the species traits (the Q-table). A Monte-Carlo permutation $(n=999)$ test was used to test the null hypothesis (H0) of absence of link between the environmental table (R) and the trait table (Q).

Thereafter, the fourth-corner statistic (Dray and Legendre, 2008) was used to test the significance of the direct trait-environment relationships on these 860 samples (430 field margins $\mathrm{x} 2$ years). This method measures the link between species traits and environmental variables using either (1) a Pearson correlation coefficient $r$ for two quantitative variables, (2) a Pearson Chi-square $\left(\chi^{2}\right)$ and G-statistic for two qualitative variables or (3) pseudo-F and a Pearson correlation coefficient $r$ for one quantitative and one qualitative variable. A permutation model was applied to test the null hypothesis (H0) that species are distributed independently of their preferences for environmental conditions and of their traits (using the 
permutation model 6 of Dray et al., 2014). We performed 49999 permutations and used the false discovery rate method (Benjamini and Hochberg 1995) to adjust $P$ values for multiple testing.

One limit of the RLQ analysis is that it only tests for the existence of a general relationship between environmental gradients and combinations of species traits, which does not allow identifying precisely which environmental variable acts on which trait. Conversely, the fourth-corner analysis does not account for the covariation among traits or among environmental variables. Therefore we combined the two analyses by applying the fourthcorner tests directly on the outputs of RLQ analysis. This latter approach consists in testing the associations between individual traits and environmental gradients obtained from RLQ scores, and between individual environmental variables and trait syndromes obtained from RLQ scores. The detailed procedure can be found in Dray et al. (2014).

The centroids and ellipses of agrotolerant and hemerophobic species were also projected as supplementary individuals on the RLQ axes to assess the response of these two broad ecological groups on the highlighted trait-environment gradients. Similarly the conventional versus organic farming systems of the fields were projected. Significant differences between the median distribution of agrotolerant and hemerophobic species on the RLQ axes on the one hand, and between conventional versus organic fields on the other hand, were tested with a Wilcoxon test.

In a second part, we modelled species richness $(S)$, relative proportion of agrotolerant $\left(S_{A}\right)$ vs. hemerophobic $\left(S_{H}\right)$ species, and functional diversity $(F D$, see below for the definition), three variables related to plant community diversity. This was done using generalized additive mixed models (GAMMs) and the gamm4 package (Wood and Scheipl, 2016) with appropriate likelihood and link function, i.e. respectively a Poisson error structure 
with a logarithm link (species richness), a binomial error structure with a logit link

(proportion of agrotolerant vs. hemerophobic species) and Gaussian error with identity link (functional diversity). The identity of the field margin was included as a random effect to account for pseudo-replication, a common issue in ecological modelling (Hurlbert, 1984). Three different models were built for the three different response variables, each including the twelve variables used in the RLQ/fourth corner analysis (i.e. ten environmental variables + day and year of observation) as potential explanatory variables. In addition, the spatial coordinates of the field margins (latitude and longitude in meters) were used to account for spatial heterogeneity that could not be properly modelled through other explanatory variables, thanks to a smooth term modelling the interaction between latitude and longitude. The degree of freedom of this smoother modelling spatial heterogeneity was left unconstrained (contrary to other covariates, see below). Local habitat structure, number of management events and year were considered as parametric coefficients, while soil $\mathrm{pH}$, soil organic matter, percentage of non-arable patches, field size, field margin width, N-Fertilization, TFI herbicides, TFI insecticides were considered as smooth terms with a limited degree of freedom $(k=5)$ to avoid overfitting. Correlations for all pairs of variables included in the analyses were well below the threshold of 0.7 (Burnham and Anderson, 2002; Freckleton, 2011, see Appendix C). All explanatory variables (except spatial coordinates) were scaled to facilitate the estimation of parameters and their interpretation (Schielzeth, 2010). Residuals were visually inspected to detect trends that could bias estimates but all assumptions of GAMMs were met. Besides examining the relationship with detailed in-field practices, we also compared $S, S_{A}, S_{H}$ and $F D$ between conventional and organic field margins with Wilcoxon tests.

Functional diversity was computed using the package BAT (Cardoso et al., 2015) and the functional diversity index introduced by Cardoso et al. (2014), which is the total branch length of a functional tree linking all species present. We used the Hill and Smith analysis 
previously performed for the RLQ analysis on the Q table (traits). The first two axes were conserved and a functional tree was built on the basis of the Euclidean distance between species in the trait multivariate space and Ward's clustering algorithm. Low functional diversity characterizes communities composed of closely related species in the trait functional space, while high functional diversity is indicative of communities with species occupying distinct and distant positions in the trait multivariate space.

\section{Results}

3.1. Impact of environmental conditions and management practices on functional composition The first two axes of the RLQ accounted for $75.1 \%$ of the total inertia (61.2 and $13.9 \%$ respectively, Figure 2). The Permutation tests indicated that the environment influences the distribution of species with fixed traits (Model 2, $P<0.001$ based on 999 permutations) and that the traits influence the composition of species assemblages found in samples with given environmental conditions (Model 4, $P<0.001$ based on 999 permutations). The first two RLQ axes accounted for most of the variance of the corresponding axes in the separate analyses of environmental descriptors ( $85.1 \%$ for the Hill and Smith analysis of the R-table) and species traits (76.8\% for the Hill and Smith analysis of the Q-table), which demonstrates the strength of the link between environmental filters (including management practices) and plant species traits in field margins.

The first RLQ axis discriminated sites according to a double gradient, related to landscape diversity and soil resources (Figure 2, Table 2). The proportion of non-arable land, the presence of a ditch, or both a ditch and a hedge within $5 \mathrm{~m}$ from the field margins as well as margin width were negatively correlated with axis 1 . Soil $\mathrm{pH}$ and clay textures were positively correlated with axis 1 . The second axis discriminated sites according to an agricultural intensification gradient with positive loadings associated with high herbicides 
use, high nitrogen fertilization level and large field size together with a high number of management events in the field margin (Figure 2, Table 2). Soil organic matter was also positively correlated with this second axis. Regarding species traits, the first axis was best correlated with traits related to the competition/disturbance trade-off: perennial, shadetolerant species with high requirement for soil moisture (Ellenberg-H) were preferentially associated with negative loadings and opposed to annuals, drought tolerant and lightdemanding (Ellenberg-L) species. On the second axis, species with rapid resource acquisition syndrome were on positive loadings associated with short height at maturity, early flowering, high SLA and high Ellenberg indicator values for nitrogen, while species with opposed features, pollinated by insects and dispersed by animals were on negative loadings. When applying the fourth corner analysis, among the 208 possible combinations of bivariate associations between traits and environmental variables, 42 were found significant (significance level $\alpha=0.05$, Figure 3a). When $P$ values were adjusted for multiple testing, 13 associations remained significant (Figure 3b). Annuals were negatively associated with margin width $\left(r=0.053, P_{a d j}=0.030\right)$, and observation date $\left(r=-0.158, P_{a d j}=0.010\right)$, while perennials showed the opposite association, and were also associated with field margins with ditches $\left(F=4807, P_{a d j}=0.030\right)$. Plant height at maturity was negatively correlated with the number of field margin management events $\left(r=-0.068, P_{a d j}=0.010\right)$, positively associated with the presence of ditches $\left(r=0.091, P_{a d j}=0.010\right)$ and negatively associated with margins with no hedge or ditch beside $\left(r=-0.073, P_{a d j}=0.010\right)$. Ellenberg indicator values for light was positively associated with margin with no hedge or ditch $\left(r=0.072, P_{a d j}=0.030\right)$, and negatively related to soil organic matter content $\left(r=-0.083, P_{a d j}=0.010\right)$. Ellenberg indicator values for soil moisture was negatively associated with soil $\mathrm{pH}\left(r=-0.123, P_{a d j}=0.010\right)$ and positively correlated with date of observation $\left(r=0.100, P_{a d j}=0.030\right)$. Finally, Ellenberg 
indicator values for nitrogen was positively correlated with the level of $\mathrm{N}$ fertilization $(r=$ $\left.0.062, P_{a d j}=0.029\right)$.

Testing directly the link between RLQ axes and traits or environment (Figure 4) showed that RLQ axis 1 was negatively correlated with soil organic matter, high proportion of non-arable habitats in the landscape, field margin width, presence of ditches, or ditches and hedges and date of observation. RLQ axis 1 was positively associated with soil $\mathrm{pH}$, number of management events on the margin, and absence of ditches or hedges. Species associated with these regularly managed, narrow field margins on high soil $\mathrm{pH}$ in arable-dominated landscapes were heliophilous and drought resistant annuals, while shade-tolerant, hygrophilous perennials were associated with large field margins on soil with elevated organic matter and presence of ditches and/or hedges in more diversified landscapes. The second RLQ axis significantly opposed sites according to soil organic matter, field size, number of field margin management events and level of $\mathrm{N}$-fertilization. Communities found in field margins with little management, adjacent to small-sized fields with low $\mathrm{N}$-fertilization input and low organic matter content contained oligotrophic species as well as a higher proportion of insect-pollinated and animal-dispersed plants.

The median of agrotolerant species was significantly different from the median of hemerophobic species both on RLQ axis 1 and axis 2, with higher values on both axes for agrotolerant species (Figure 5), i.e. agrotolerant species were associated with disturbed field margins (RLQ axis 1) adjacent to fields with intensive farming practices (RLQ axis 2). The position of field margins adjacent to conventional fields was not different from those adjacent to organic fields on RLQ axis 1 but they were significantly higher on RLQ axis 2 (Figure 6), which was expected because farming system (conventional vs. organic) recapitulates farming practices encapsulated in RLQ axis 2 ( $\mathrm{N}$ fertilization and pesticides). 
3.2. Impact of environmental conditions and management practices on taxonomic and functional diversity

In all three generalized additive mixed models (whose adjusted $\mathrm{R}^{2}$ values were $0.34,0.31$ and 0.30 for species richness, relative proportion of agrotolerant species and functional diversity respectively), the spatial term absorbed a lot of the deviance by delimiting areas with contrasting spatial structure for the response variable (see Appendix D). In addition to these spatial effects, species richness in field margins decreased linearly with increasing field size (Chi sq. $=12.83, P<0.001)$ and decreasing soil organic matter $($ Chi sq. $=5.61, P=0.018)$ with similar magnitude $\left(\beta_{\text {Field size }}=-0.07 \pm 0.02\right.$ and $\left.\beta_{\text {Soil organic matter }}=0.06 \pm 0.028\right)$ and responded negatively to the frequency index of herbicides use, although with a lower slope $\left(\beta_{\text {TFI herbicides }}\right.$ $=-0.028 \pm 0.014$, Figure 7a, Appendix E). Functional diversity was related similarly to these two variables: linearly with field size $(F=12.08, P<0.001)$ and in a slightly non-linear way with soil organic matter $(F=5.91, P=0.030)$, with slopes of similar magnitude (see Figure $7 b)$. The proportion of agrotolerant relative to hemerophobic species depended on field boundary structure, with more agrotolerant species in the absence of a ditch or hedge $(z=2.32, P=0.020)$. The proportion of agrotolerant species also increased with decreasing field margin width (Chi sq. $=5.33, P=0.021)$ and increasing soil $\mathrm{pH}(\mathrm{Chi} . \mathrm{sq}=4.769, P=0.029)$, with a weaker effect for field margin width than for soil $\mathrm{pH}\left(\beta_{\text {Margin width }}=-0.065 \pm 0.03\right.$ and $\beta_{\text {Soil } p H}=0.1 \pm 0.045$, Figure $7 \mathrm{c})$.

With an average of $16.53 \pm 6.38$ species, organic field margins were richer than conventional field margins $(14.07 \pm 6.61$ species; Student t-test, $t=3.690, P<0.001)$. This difference was caused mainly by hemerophobic species whose number was significantly higher in organic (9.34 \pm 5.29$)$ than in conventional (7.49 \pm 4.89$)$ field margins $(t=3.509, P=0.001)$ with 
smaller but nonetheless significant differences regarding agrotolerant species $(7.19 \pm 3.24$ and $6.58 \pm 3.26$ respectively, Student t-test, $t=1.841, P=0.022)$. Functional diversity was also higher in organic $(\mathrm{FD}=125.83 \pm 27.69)$ compared with conventional field margins $(\mathrm{FD}=114.95 \pm 29.63$, Student t-test, $t=4.774, P<0.001)$.

\section{Discussion}

The aim of the study was to test the relationships between plant traits and environmental and management conditions in field margins, and to identify the main factors structuring field margin vegetation. The first gradient discriminating field margin vegetation at the nationwide level depended on field boundary "naturalness" (landscape diversity, field boundary structure, margin width and number of management events). The second gradient was based on the intensity of in-field management (amount of nitrogen fertilizers, field size). Field margin vegetation was thus structured by two independent gradients of disturbances and fertility. We showed that these gradients were associated with particular plant trait syndromes including life cycle duration, plant height, mode of pollination and dispersal as well as responses to light, soil moisture and nitrogen. Broad classification of species into agro-tolerant versus hemerophobic species, and management practices into conventional versus organic, were also distinctly distributed on the RLQ axes showing the consistency of these groupings. Species richness and functional diversity were primarily correlated with landscape heterogeneity (field size) and abiotic factors (soil organic matter), with species richness also decreasing with the frequency index of herbicides use. The relative proportion of agrotolerant versus hemerophobic species changed with soil $\mathrm{pH}$ and was also related to more local factors such as margin width and field boundary structure. 
423

424

The level of disturbances incurred by field margins via direct management appeared as the main factor structuring the functional composition of the vegetation. As expected, it opposed small annual agro-tolerant species in narrow, frequently managed margins to taller perennial hemerophobic species in wider, less frequently managed margins. The accumulation of recurring disturbances such as mowing can create bare soil for colonization and transient establishment of annual species able to use resources rapidly (Kleijn, 1997).

In our dataset, this gradient of disturbance was also correlated with the proportion of nonarable crop habitats in the landscape and with the diversity of the field boundary structure, especially the presence of ditches and/or hedges. The combination of these local and landscape elements creates a diversity of environmental conditions that is suitable for various hemerophobic species. Hence, the above-mentioned factors generate a gradient from moist and shady conditions (i.e. ditch verges with tree layer) with hygrophilous and shade-tolerant species typical of wetlands such as Lysimachia vulgaris or Mentha suaveolens, to open dry conditions (i.e. open road verges) with heliophilous and drought tolerant species (Erodium cicutarium, Echium plantagineum). Our study confirms the importance of this gradient in a different context (Western Europe) and at a wider spatial scale, similarly to the gradient observed in a region of Estonia (Aavik et al., 2008, 2010).

This double gradient of boundary management intensity and naturalness was not related to a gradient of species richness but it did influence the richness of agrotolerant and hemerophobic species. General theory concerning diversity-area relations predicts that larger margins will support richer communities. Our standardized protocol measuring species richness on $10 \mathrm{~m}^{2}$ equidistant from the field and the adjacent habitat excludes this type of effect (that may however still exist on the larger landscape level). Instead, the width of the field margin 
determines higher buffering capacities relative to within field practices (De Cauwer et al.,

447 2006) and higher environmental quality in the interior of the margin (Aavik and Liira, 2010).

448 Thus it is not surprising that species richness on the whole was unaffected by field margin

449

450

width, while as expected, more agrotolerant species were observed on narrow margins which reflects the higher influence of in-field management practices in this type of margins.

Conventional and organic field margins were not different on this gradient, which suggests that some field margins of organic farms can be managed intensively (e.g., field margins next to roads, managed by regional or local authorities), while conversely some conventional farmers maintain margins with diversified local habitat structure.

4.2. Resource gradient associated with agricultural intensification and non-intended effects of in-field practices

The second structuring factor was related to in-field practices (fertilization, herbicides), field size and again the frequency of field margin management. It opposes smallsized nitrophilous species, with early flowering and rapid acquisition resource capacity (SLA) in margins of large, intensively managed crop fields, to taller, later flowering and less nitrogen-demanding species with slower resource acquisition in smaller, less intensively managed crop fields. Specific bivariate association between practices and species traits showed that this gradient was mainly driven by the dose of in-field nitrogen fertilizers and the proportion of nitrophilous species. Contrary to our expectations, we did not find any particular traits associated with more intensive uses of herbicides within the field. However, there was a significant negative effect of the frequency index of herbicide use within the field on species richness in the field margin. This result is consistent with several fine scale experiments that showed a delayed flowering onset and a reduced flower number for plants 
exposed to herbicide drift at $\sim 1 \%$ of the field application rate (Bohnenblust et al., 2016) or a reduction of species richness in plant communities exposed to increasing doses of glyphosate applied at drift levels, from 0 to $25 \%$ of the counselled rate (Pelissier et al., 2014). Decreased species richness combined with an absence of effects on functional diversity or composition suggests that the loss of species due to the intensity of herbicide use is not determined by the ten traits used in our classification. Other traits such as plant morphology or leaf surface traits, including cuticle characteristics, hairiness (e.g. density of trichomes), density of stomata or cell size, may be more relevant for sensitivity to herbicides, as they are related to the wetting and the penetration of foliar applied herbicides and therefore their bioavailability within the plant (Gaba et al., 2017). Alternatively, opposite responses of plant traits, such as height or SLA, to herbicides vs. fertilizers (Pellissier et al. 2014) may have hampered our ability to detect trait-based changes in community composition.

The effect of nitrogen fertilizer input to the crop on the richness or composition of the vegetation of field margin has been reported previously (e.g., Kleijn and Verbeek, 2000 ; Pélissier et al., 2014) and this drift was also confirmed in our study. In addition to earlier studies, the fourth corner test in our study demonstrates the direct link between the abundance of high-nitrogen demanding species (species with high Ellenberg-N values) in the field margin and the amount of nitrogen fertilizer applied within the field. This suggests a strong shift in species composition following higher resource supply. However, contrary to other studies, the high levels of fertilization were not associated with a decrease in species richness. The expected negative relationship between fertility and species richness (Tilman, 1993) is attributable both to increased living biomass and litter accumulation that reduce light to very low levels and thus inhibit germination and/or survival of seedlings, and decrease rates of establishment of new species (Foster and Gross, 1998). The same processes are at play in arable field margins where higher nutrient application levels on the field generally increases 
field margin biomass (Kleijn, 1996). However, disturbances created by field margin direct management can maintain gaps with less competitive annual species. Overall, the larger area covered by our study (the whole of metropolitan France) compared to previous field boundary studies, showed that species richness depends primarily on the natural soil trophic gradient, which opposes species rich communities on organic-rich acidic soils, versus poorer communities on organic-poor basic clay soils (Manhoudt et al., 2007).

Species depending on animals for their reproduction (obligate entomogamous species) or for their dispersal (zoochorous species) were associated with smaller less intensively managed fields in landscapes with a high proportion of non-arable habitats. Several processes may be at play, which are difficult to disentangle. Small fields mean higher configurational heterogeneity of landscapes (Fahrig et al., 2011) with more numerous linear elements that can act as corridors needed for the stability of some animal populations (Marshall and Moonen, 2002; Molina et al., 2014). The higher proportion of non-arable habitats has also been shown to favor animal diversity in agricultural landscapes (Weibull et al., 2000) through dispersal from these habitats to field margins. More generally, the negative link of plants depending on animals with RLQ axis 2 suggests that the absence of these species could be a consequence of agricultural intensification. According to the fourth corner analysis none of the within field practices of the contemporary years (dose of nitrogen fertilizer, intensity of herbicides or insecticides use) were related to the presence of this group of species. However, the strong link of dispersal and pollination modes with RLQ axis 2 (related to agricultural intensification) might suggest that the presence/absence of entomogamous and animaldispersed species is rather a result of the interactions of cumulative management practices over several years and their interactions with large scale factors (field size, landscape, Roschewitz et al., 2005). 
Relative proportion of agrotolerant and hemerophobic species could not be directly related to one of these agricultural intensification factors. However, the distribution of agrotolerant species was clearly more associated with positive values of RLQ axis 2 which means a response to a combination of high input of agrochemicals (fertilizer, herbicides) and large field size. Our general result on this agricultural intensification axis is consistent with previous studies showing that among agrochemicals, the effect of fertilizers on plant community composition in field margins is always stronger than the effect of herbicides (Kleijn and Snoeijing, 1997).

\subsection{Implications for management of biodiversity in field margins}

It is recognized that species richness is not necessarily the most suitable indicator of healthy field margins because some species are known to respond positively to disturbances and/or excess of nitrogen fertilizers. Following that idea, Aavik and Liira (2009) introduced a classification in two groups, agrotolerant species and hemerophobic species, on the basis of their capacity to persist in arable fields with modern cultivation practices (i.e., present in more than $10 \%$ of the agricultural fields of the studied region). With our trait-based approach that links directly environmental conditions and plant traits, we can confirm the utility of this broad classification and characterize the functional profile of species associated with undisturbed field margins adjacent to low input fields. Our RLQ axes reflect two independent dimensions of field margin disturbances (axis 1) and agricultural intensification (axis 2). The position of agrotolerant and hemerophobic species on these two axes is consistent with what was expected. Therefore one can identify factors promoting hemerophobic species. On the whole, their presence increases with field margin width, presence of semi-natural elements such as ditches and hedges, high proportion of non-arable land, small field size, low number 
of management events and low amounts of nitrogen fertilizer input. Associated traits include species with a perennial life cycle, a high stature at maturity, low nitrogen requirements, pollination by insects and dispersion by animals. As found in previous studies (e.g. Bengtsson et al. 2005 for a review), organic field margins have higher species richness than conventional field margins. Interestingly, the higher species richness in organic field margins is due, at $75 \%$, to a higher number of hemerophobic species. Differences on the RLQ trait-environment multivariate space showed that organic field margins differed from conventional field margins on the agricultural intensification axis with fewer nitrogen-demanding species, more insectpollinated species and more animal-dispersed species.

\section{Conclusions}

With the aim of detecting non-intended effects of agrochemicals on non-targeted plants, our study highlighted that the composition and the diversity of vegetation in arable field margins were primarily driven by the direct field margin management and by landscape factors.

However, among farming practices, distinct non-intended effects of fertilization and herbicides were highlighted. The level of nitrogen fertilizers had the strongest effects on the functional composition of field margin vegetation with a change toward more nutrientdemanding species, while the intensity of herbicides use was related to a slight decrease in species richness with no effects on functional composition or diversity. A better understanding of the effect of herbicide drift on non-target plant communities will require a finer characterization of herbicides modes of action, as well as data on species traits related to herbicides sensitivity, which will be the aim of further analyses.

Acknowledgements: The 500 ENI network is developed by the French Ministry of Agriculture under the Ecophyto framework with funding from the Agence Française de la 
568 Biodiversité. We thank all the people that have collected the data in the field, the farmers who 569 provided information on their practices as well as all the people involved in the coordination 570 of the network: Camila Andrade (MNHN), Jérôme Jullien (DGAL-Ministry of Agriculture), 571 Nicolas Lenne (DGAL-Ministry of Agriculture), Pascal Monestiez (INRA) and the GT Stats 572500 ENI. We also thank Marie Carles and Gérard Balent (INRA) for providing the landscape 573 composition metrics and Jon Marshall and one anonymous reviewer for their constructive 574 comments that helped us improving the manuscript. 


\section{References}

Aavik, T., Augenstein, I., Bailey, D., Herzog, F., Zobel, M., Liira, J., 2008. What is the role of local landscape structure in the vegetation composition of field boundaries? Applied Vegetation Science 11, 375-386.

Aavik, T., Liira, J., 2009. Agrotolerant and high nature-value species-Plant biodiversity indicator groups in agroecosystems. Ecological Indicators 9, 892-901.

Aavik, T., Liira, J., 2010. Quantifying the effect of organic farming, field boundary type and landscape structure on the vegetation of field boundaries. Agriculture, Ecosystems and Environment 135, 178-186.

Alignier, A. 2018. Two decades of change in a field margin vegetation metacommunity as a result of field margin structure and management practice changes. Agriculture, Ecosystems and Environment 251, 1-10.

Alignier, A., Baudry, J., 2015. Changes in management practices over time explain most variation in vegetation of field margins in Brittany, France. Agriculture, Ecosystems \& Environment 211, 164-172.

Bassa, M., Boutin, C., Chamorro, L., Sans, F.X., 2011. Effects of farming management and landscape heterogeneity on plant species composition of Mediterranean field boundaries. Agriculture, Ecosystems \& Environment 141, 455-460.

Bengtsson, J., Ahnström, J., Weibull, A.C., 2005. The effects of organic agriculture on biodiversity and abundance: a meta-analysis. Journal of Applied Ecology 42, 261-269.

Benjamini, Y., Hochberg, Y., 1995. Controlling the false discovery rate: a practical and powerful approach to multiple testing. Journal of the royal statistical society. Series B (Methodological), 289-300. 
Benton, T.G., Bryant, D.M., Cole, L., Crick, H.Q., 2002. Linking agricultural practice to insect and bird populations: a historical study over three decades. Journal of Applied Ecology 39, 673-687.

Bohnenblust, E.W., Vaudo, A.D., Egan, J.F., Mortensen, D.A., Tooker, J.F., 2016. Effects of the herbicide dicamba on nontarget plants and pollinator visitation. Environmental Toxicology and Chemistry 35, 144-151.

Boutin, C., Jobin, B., 1998. Intensity of agricultural practices and effects on adjacent habitats. Ecological Applications 8, 544-557.

Brittain, C., Potts, S.G., 2011. The potential impacts of insecticides on the life-history traits of bees and the consequences for pollination. Basic and Applied Ecology 12, 321-331.

Burnham, K., Anderson, D., 2002. Model selection and multimodel inference: a practical information-theoretic approach. Springer, New York.

Cardoso, P., Rigal, F., Borges, P.A.V., Carvalho, J.C., 2014. A new frontier in biodiversity inventory: A proposal for estimators of phylogenetic and functional diversity. Methods in Ecology and Evolution 5, 452-461.

Cardoso, P., Rigal, F., Carvalho, J.C., 2015. BAT - Biodiversity Assessment Tools, an R package for the measurement and estimation of alpha and beta taxon, phylogenetic and functional diversity. Methods in Ecology and Evolution 6, 232-236.

Chaudron C, Perronne R, Di Pietro F., 2018. Functional response of plant assemblages to management practices in road-field boundaries. Applied Vegetation Science 21, 33-44.

De Cauwer, B., Reheul, D., Nijs, I., Milbau, A., 2006. Effect of margin strips on soil mineral nitrogen and plant biodiversity. Agronomy for Sustainable Development 26, 117-126. 
620

621

622

623

624

625

626

627

628

629

630

631

632

633

634

635

636

637

638

639

640

De Snoo, G.R., Van Der Poll, R.J., 1999. Effect of herbicide drift on adjacent boundary vegetation. Agriculture, Ecosystems and Environment 73, 1-6.

Dolédec, S., Chessel, D., ter Braak, C.J., Champely, S., 1996. Matching species traits to environmental variables: a new three-table ordination method. Environmental and Ecological Statistics 3, 143-166.

Donald, P., Green, R., Heath, M., 2001. Agricultural intensification and the collapse of Europe's farmland bird populations. Proceedings of the Royal Society of London B: Biological Sciences 268, 25-29.

Douma, J., Shipley, B., Witte, J.-P., Aerts, R., Van Bodegom, P., 2012. Disturbance and resource availability act differently on the same suite of plant traits: revisiting assembly hypotheses. Ecology 93, 825-835.

Dray, S., Choler, P., Dolédec, S., Peres-Neto, P.R., Thuiller, W., Pavoine, S., ter Braak, C.J.F., 2014. Combining the fourth-corner and the RLQ methods for assessing trait responses to environmental variation. Ecology 95, 14-21.

Dray, S., Legendre, P., 2008. Testing the species traits-environment relationships: the fourth-corner problem revisited. Ecology 89, 3400-3412.

Fahrig, L., Baudry, J., Brotons, L., Burel, F.G., Crist, T.O., Fuller, R.J., Sirami, C., Siriwardena, G.M., Martin, J.L., 2011. Functional landscape heterogeneity and animal biodiversity in agricultural landscapes. Ecology Letters 14, 101-112.

Foster, B. L., Gross, K. L., 1998. Species richness in a successional grassland: effects of nitrogen enrichment and plant litter. Ecology, 79, 2593-2602. 
Freckleton, R. P., 2011. Dealing with collinearity in behavioural and ecological data: model averaging and the problems of measurement error. Behavioral Ecology and Sociobiology 65, $91-101$

Fried, G., Norton, L.R., Reboud, X., 2008. Environmental and management factors determining weed species composition and diversity in France. Agriculture Ecosystems \& Environment 128, 68-76.

Fried, G., Petit, S., Dessaint, F., Reboud, X., 2009. Arable weed decline in Northern France: Crop edges as refugia for weed conservation? Biological Conservation 142, 238-243.

Gaba, S., Perronne, R., Fried, G., Gardarin, A., Bretagnolle, F., Biju-Duval, L., Colbach, N., Cordeau, S., Fernández-Aparicio, M., Gauvrit, C., Gibot-Leclerc, S., Guillemin, J.-P., Moreau, D., Munier-Jolain, N., Strbik, F., Reboud, X., 2017. Response and effect traits of arable weeds in agro-ecosystems: a review of current knowledge. Weed Research 57, 123 147.

Gabriel, D., Thies, C., Tscharntke, T., 2005. Local diversity of arable weeds increases with landscape complexity. Perspectives in Plant Ecology, Evolution and Systematics 7, 85-93.

Garnier, E., Navas, M.-L., 2012. A trait-based approach to comparative functional plant ecology: concepts, methods and applications for agroecology. A review. Agronomy for Sustainable Development 32, 365-399.

Greaves, M.P., Marshall, E.J.P., 1987. Field margins: definitions and statistics. In: Way, J.M., Greig-Smith, P.J. (Eds.), Field Margins, vol. 35. British Crop Protection Council, Thornton Heath, Surrey, London, pp. 3-10.

Grime, J.P., 2006. Trait convergence and trait divergence in herbaceous plant communities: Mechanisms and consequences. Journal of Vegetation Science 17, 255-260. 
Halberg, N., 1999. Indicators of resource use and environmental impact for use in a decision aid for Danish livestock farmers. Agriculture, Ecosystems \& Environment 76, 17-30.

Hengl, T., Mendes de Jesus, J., Heuvelink, G.B.M., Ruiperez Gonzalez, M., Kilibarda, M., Blagotić, A., Shangguan, W., Wright, M.N., Geng, X., Bauer-Marschallinger, B., Guevara, M.A., Vargas, R., MacMillan, R.A., Batjes, N.H., Leenaars, J.G.B., Ribeiro, E., Wheeler, I., Mantel, S., Kempen, B., 2017. SoilGrids250m: Global gridded soil information based on machine learning. PLoS One 12, e0169748.

Hill, M., Smith, A., 1976. Principal component analysis of taxonomic data with multi-state discrete characters. Taxon, 249-255.

Hurlbert, S. H., 1984. Pseudoreplication and the design of ecological field experiments. Ecological Monographs 54, 187-211.

Kleijn, D., 1996. The use of nutrient resources form arable fields by plants in field boundaries. Journal of Applied Ecology 33, 1433-1440.

Kleijn, D. 1997. Species richness and weed abundance in the vegetation of arable field boundaries. Ph.D. thesis, Agricultural University, Wageningen.

Kleijn, D., Snoeijing, G. I. J., 1997. Field boundary vegetation and the effects of agrochemical drift: botanical change caused by low levels of herbicide and fertilizer. Journal of Applied Ecology 34, 1413-1425.

Kleijn, D., Verbeek, M., 2000. Factors affecting the species composition of arable field boundary vegetation. Journal of Applied Ecology 37, 256-266.

Lavorel, S., Garnier, E., 2002. Predicting changes in community composition and ecosystem functioning from plant traits: Revisiting the Holy Grail. Functional Ecology 16, 545-556. 
Manhoudt, A.G.E., Visser, A.J., de Snoo, G.R., 2007. Management regimes and farming practices enhancing plant species richness on ditch banks. Agriculture, Ecosystems and Environment 119, 353-358.

Marshall, E.J.P., Moonen, A.C., 2002. Field margins in northern Europe: their functions and interactions with agriculture. Agriculture, Ecosystems \& Environment 89, 5-21.

Molina, G.A., Poggio, S.L., Ghersa, C.M., 2014. Epigeal arthropod communities in intensively farmed landscapes: effects of land use mosaics, neighbourhood heterogeneity, and field position. Agriculture, Ecosystems \& Environment 192, 135-143.

Pellissier, L., Wisz, M.S., Strandberg, B., Damgaard, C., 2014. Herbicide and fertilizers promote analogous phylogenetic responses but opposite functional responses in plant communities. Environmental Research Letters 9.

Petersen, S., Axelsen, J.A., Tybirk, K., Aude, E., Vestergaard, P., 2006. Effects of organic farming on field boundary vegetation in Denmark. Agriculture, Ecosystems and Environment 113, 302-306.

Robinson, R.A., Sutherland, W.J., 2002. Post-war changes in arable farming and biodiversity in Great Britain. Journal of Applied Ecology 39, 157-176.

Roschewitz, I., Gabriel, D., Tscharntke, T., Thies, C., 2005. The effects of landscape complexity on arable weed species diversity in organic and conventional farming. Journal of Applied Ecology 42, 873-882.

Schielzeth, H., 2010. Simple means to improve the interpretability of regression coefficients. Methods in Ecology and Evolution 1, 103-113.

Steffan-Dewenter, I., Tscharntke, T., 1999. Effects of habitat isolation on pollinator communities and seed set. Oecologia 121, 432-440. 
709 Stoate, C., Boatman, N., Borralho, R., Carvalho, C.R., De Snoo, G., Eden, P., 2001.

710 Ecological impacts of arable intensification in Europe. Journal of Environmental

$711 \quad$ Management 63, 337-365.

712 Tarmi, S., Helenius, J., Hyvönen, T., 2009. Importance of edaphic, spatial and management

713 factors for plant communities of field boundaries. Agriculture, Ecosystems and

$714 \quad$ Environment 131, 201-206.

715 Tilman, D., 1993. Species richness of experimental productivity gradients: how important is $716 \quad$ colonization limitation? Ecology 74, 2179-2191.

717 Weibull, A.-C., Bengtsson, J., Nohlgren, E., 2000. Diversity of butterflies in the agricultural

718 landscape: the role of farming system and landscape heterogeneity. Ecography 23, 743719750.

720 Wood, S., Scheipl, F. 2016. gamm4: Generalized Additive Mixed Models using 'mgcv' and

721 'lme4'. R package version 0.2-4. https://CRAN.R-project.org/package=gamm4 
Table 1. List of selected traits with their abbreviations, units, and the management practices likely to affect these traits based on ecological mechanisms: Dist. $=$ Disturbance, Res. $=$ Resources.

\begin{tabular}{|c|c|c|}
\hline Traits & Ecological mechanisms & Expected responses in field margin strips \\
\hline $\begin{array}{l}\text { Life form } \\
\text { (annual/perennial) }\end{array}$ & Dist. & $\begin{array}{l}\text { Field margin strip management frequency favours annuals; Field } \\
\text { margin strip width favour perennials; herbicide drift favours } \\
\text { agrotolerant (annual) species. }\end{array}$ \\
\hline $\begin{array}{l}\text { Plant height at } \\
\text { maturity }(\mathrm{cm})\end{array}$ & Dist. (+Res.) & $\begin{array}{l}\text { Field margin strip management frequency favours short species } \\
\text { Plant height increases with resources (fertile soils, } \mathbf{N} \text { Fertilisation) }\end{array}$ \\
\hline Seed mass (mg) & Dist., Res. & $\begin{array}{l}\text { Seed size/number trade-off : disturbed field margins favour species } \\
\text { producing numerous small seeds (ruderal strategy) while stable field } \\
\text { margins favour species producing fewer seeds each with higher seed } \\
\text { mass (competitive strategy) }\end{array}$ \\
\hline $\begin{array}{l}\text { Specific Leaf Area, } \\
\text { SLA }\left(\mathrm{mm}^{2} \cdot \mathrm{mg}^{-1}\right)\end{array}$ & Res.(+Dist.) & $\begin{array}{l}\text { N fertilization, Soil fertility (Organic matter), and Field margin } \\
\text { strip management frequency favour species with high resource } \\
\text { acquisition capacity (high SLA) }\end{array}$ \\
\hline $\begin{array}{l}\text { Flowering onset } \\
\text { (month) }\end{array}$ & Dist. (+Res.) & $\begin{array}{l}\text { Field margin strip management frequency favours early flowering } \\
\text { species }\end{array}$ \\
\hline Ellenberg-N (EIV-N) & Res. (soil N) & $\begin{array}{l}\text { High } \mathbf{N} \text { fertilization, fertile soils favour nitrogen-demanding species } \\
\text { (high EIV-N) or tall competitive species. }\end{array}$ \\
\hline Ellenberg-H (EIV-H) & Res. (water availability) & Presence of ditches favours hygrophilous species (high EIV-H) \\
\hline Ellenberg-L (EIV-L) & Res. (Light availability) & Presence of hedges favours shade-tolerant species (low EIV-L) \\
\hline $\begin{array}{l}\text { Mode of pollination } \\
\text { Mode of dispersal }\end{array}$ & Biotic interactions, Landscape & $\begin{array}{l}\text { Plants dependent on animal for reproduction and dispersion may be } \\
\text { less frequent in simplified landscapes (openfield), pollinated plants } \\
\text { may also decrease with insecticide use. }\end{array}$ \\
\hline
\end{tabular}


Table 2. List of management practices and selected traits with their abbreviations, units, basic statistics and their coordinates on the first two RLQ axes.

\begin{tabular}{|c|c|c|c|}
\hline Environmental Variables & $\begin{array}{l}\text { Mean (Min-Max) } \\
\text { or counts }\end{array}$ & RLQ axis 1 & RLQ axis 2 \\
\hline \multicolumn{4}{|l|}{ Soil } \\
\hline Soil $\mathrm{pH}$ and texture gradient (soil $\mathrm{pH}$ ) & $6.89(5.39-7.83)$ & 0.501 & 0.248 \\
\hline Soil organic matter (soil OM) (ppm) & $19.08(5.71-53.29)$ & -0.322 & 0.486 \\
\hline \multicolumn{4}{|l|}{ Landscape } \\
\hline Non-arable land [\%] & $16.68(0-90.16)$ & -0.253 & -0.218 \\
\hline Field size [ha] & $7.47(0.005-40)$ & -0.112 & 0.391 \\
\hline \multicolumn{4}{|l|}{ Boundary type } \\
\hline Ditch & $n=46$ & -0.812 & -1.169 \\
\hline Ditch and hedge & $n=12$ & -1.012 & 0.738 \\
\hline Hedge & $n=49$ & -0.036 & 0.250 \\
\hline Other boundary type & $n=323$ & 0.170 & 0.118 \\
\hline \multicolumn{4}{|l|}{ Field Margin } \\
\hline Margin width [m] & $3.13(1-10)$ & -0.141 & 0.029 \\
\hline Number of management events (N. Mgt events) & $1.18(1-3)$ & 0.171 & 0.311 \\
\hline \multicolumn{4}{|l|}{ In-field farming practices } \\
\hline 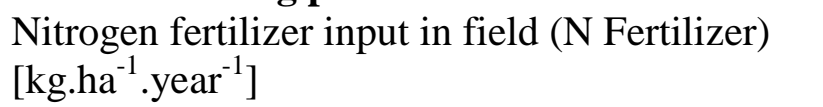 & $119.17(0-500)$ & -0.083 & 0.397 \\
\hline TFI Herbicides (TFI Herbi) & $0.94(0-3)$ & -0.037 & 0.156 \\
\hline TFI Insecticides (TFI Insec) & $0.21(0-3.90)$ & 0.078 & 0.059 \\
\hline \multicolumn{4}{|l|}{ Temporal variables } \\
\hline Date (number of days since January $1 \mathrm{st}$ ) & $175(116-276)$ & -0.607 & 0.165 \\
\hline Year 2013 & $n=430$ & 0.101 & 0.024 \\
\hline Year 2014 & $n=430$ & -0.102 & -0.024 \\
\hline \multicolumn{4}{|l|}{ Traits } \\
\hline \multicolumn{4}{|l|}{ Lifeform } \\
\hline Annual & $n=84$ & 0.915 & -0.281 \\
\hline Perennial & $n=102$ & -0.388 & 0.119 \\
\hline Plant height $[\mathrm{cm}]$ & $122.18(20-3000)$ & -0.170 & -0.493 \\
\hline Seed mass $[\mathrm{mg}]$ & $5.09(0.02-193.6)$ & 0.225 & -0.313 \\
\hline Specific Leaf Area (SLA) $\left[\mathrm{mm}^{2} . \mathrm{mg}^{-1}\right]$ & $26.19(6.50-53.68)$ & 0.096 & 0.194 \\
\hline Flowering onset (Flow. On.) & $5.11(1-9)$ & -0.138 & -0.375 \\
\hline \multicolumn{4}{|l|}{ Pollination mode (Polli.) } \\
\hline Entomogamous & $n=60$ & -0.247 & -0.646 \\
\hline Other (wind, water, autogamous) & $n=126$ & 0.064 & 0.170 \\
\hline \multicolumn{4}{|l|}{ Mode of dispersal (Disp.) } \\
\hline By animals & $n=77$ & -0.242 & -0.689 \\
\hline By other means & $n=109$ & 0.143 & 0.407 \\
\hline Ellenberg indicator values for Light (EIV-L) & $7.20(4-9)$ & 0.422 & -0.057 \\
\hline $\begin{array}{l}\text { Ellenberg indicator values for soil moisture } \\
\text { (EIV-H) }\end{array}$ & $4.78(1-8)$ & -0.554 & 0.154 \\
\hline Ellenberg indicator values for nitrogen (EIV-N) & $6.24(1-9)$ & -0.026 & 0.172 \\
\hline
\end{tabular}




\section{Figure captions}

Figure 1. Distribution map of the 430 field margins surveyed in France. Colors correspond to the different production systems: wheat (black), maize (red), market gardening centred on lettuce production (green) and vineyards (blue). The black lines represent the limit of departments, a French administrative unit dividing metropolitan France into 95 units.

Figure 2. Results of the first two axes of the RLQ analysis: (a) scores of species, (b) coefficients for environmental variables, and (c) traits. The values of $d$ give the grid size. Codes for variables and traits are given in Tables 1 and 2; codes for species in Appendix B.

Figure 3. Results of the fourth-corner tests. a) Significant $(P<0.05)$ positive associations are represented by red cells, and significant negative associations by blue cells. Nonsignificant associations are in grey. Black lines separate different variables; white lines separate different modalities for categorical variables. b) The same associations when $P$ values were adjusted for multiple comparisons using the false discovery rate procedure. Codes for traits and variables are given in Tables 1 and 2.

Figure 4. a) Fourth-corner tests between the first two RLQ axes for environmental gradients (AxcR1/AxcR2) and traits. (b) Fourth-corner tests between the first two RLQ axes for trait syndromes (AxQ1 and AxQ2) and environmental variables. Positive significant associations are represented by red cells, and negative significant associations by blue cells.

Figure 5. a) Projection of agrotolerant versus hemerophobic species as supplementary variables in the RLQ analysis. The value of $d$ gives the grid size. Comparison of the distribution of agrotolerant versus hemerophobic species on b) RLQ axis 1 and c) RLQ axis 2. The values of Wilcoxon test statistic $W$ and the associated $P$-values are provided on the graphs.

Figure 6. a) Projection of organic versus conventional field margin strips as supplementary variables in the RLQ analysis. The value of $d$ gives the grid size. Comparison of the distribution of organic (org.) versus conventional (conv.) field margin strips on b) RLQ axis 1 and c) RLQ axis 2 The values of Wilcoxon test statistic $W$ and the associated $P$-values are provided on the graphs.

Figure 7. Scaled response of a) species richness, b) functional diversity and c) proportion of agrotolerant species to significant continuous variables identified in Generalized Additive Mixed Models (see Appendix E). TFI herbicides = Treatment frequency index of herbicides. 
Figure 1.

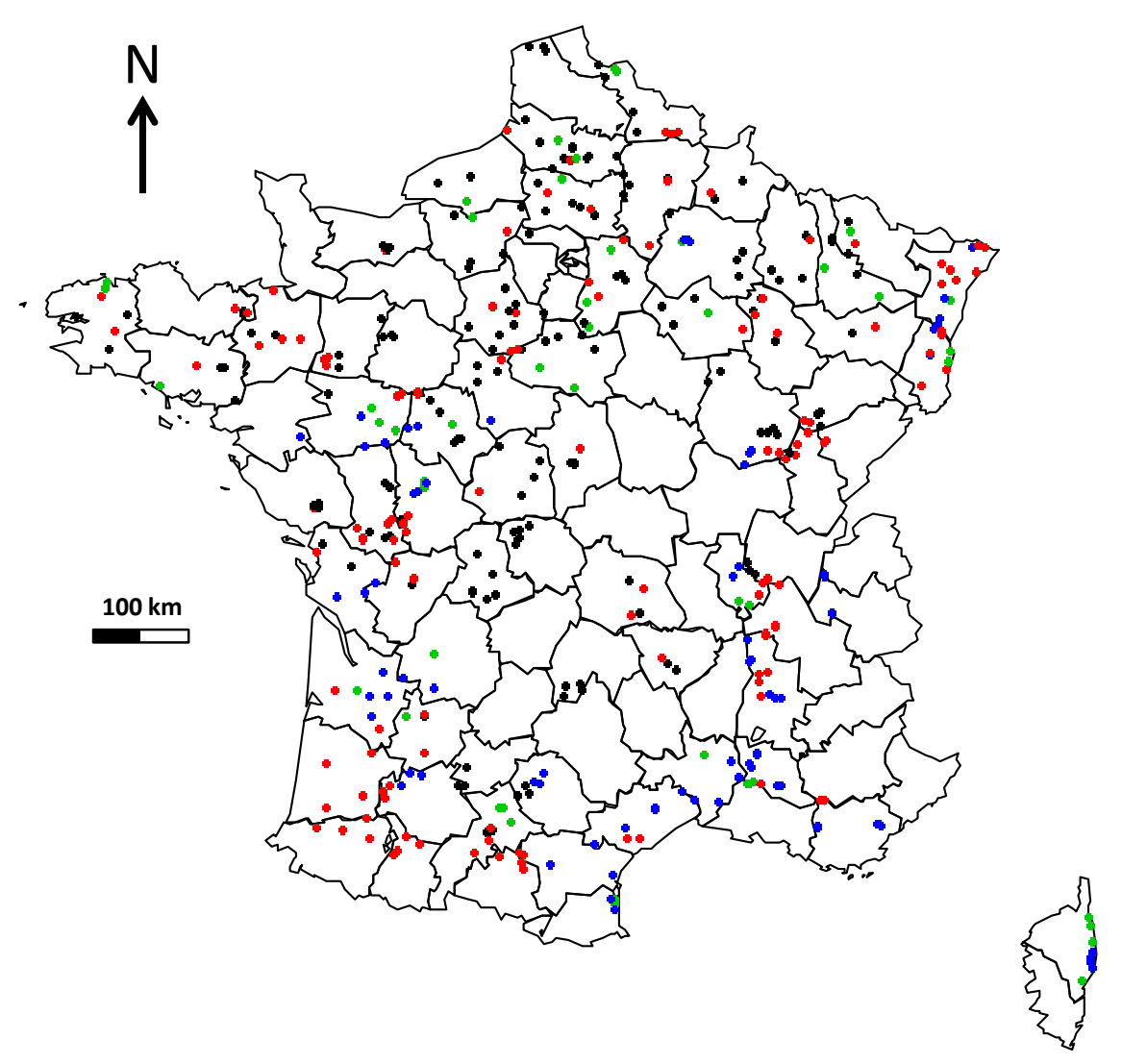


Figure 2.
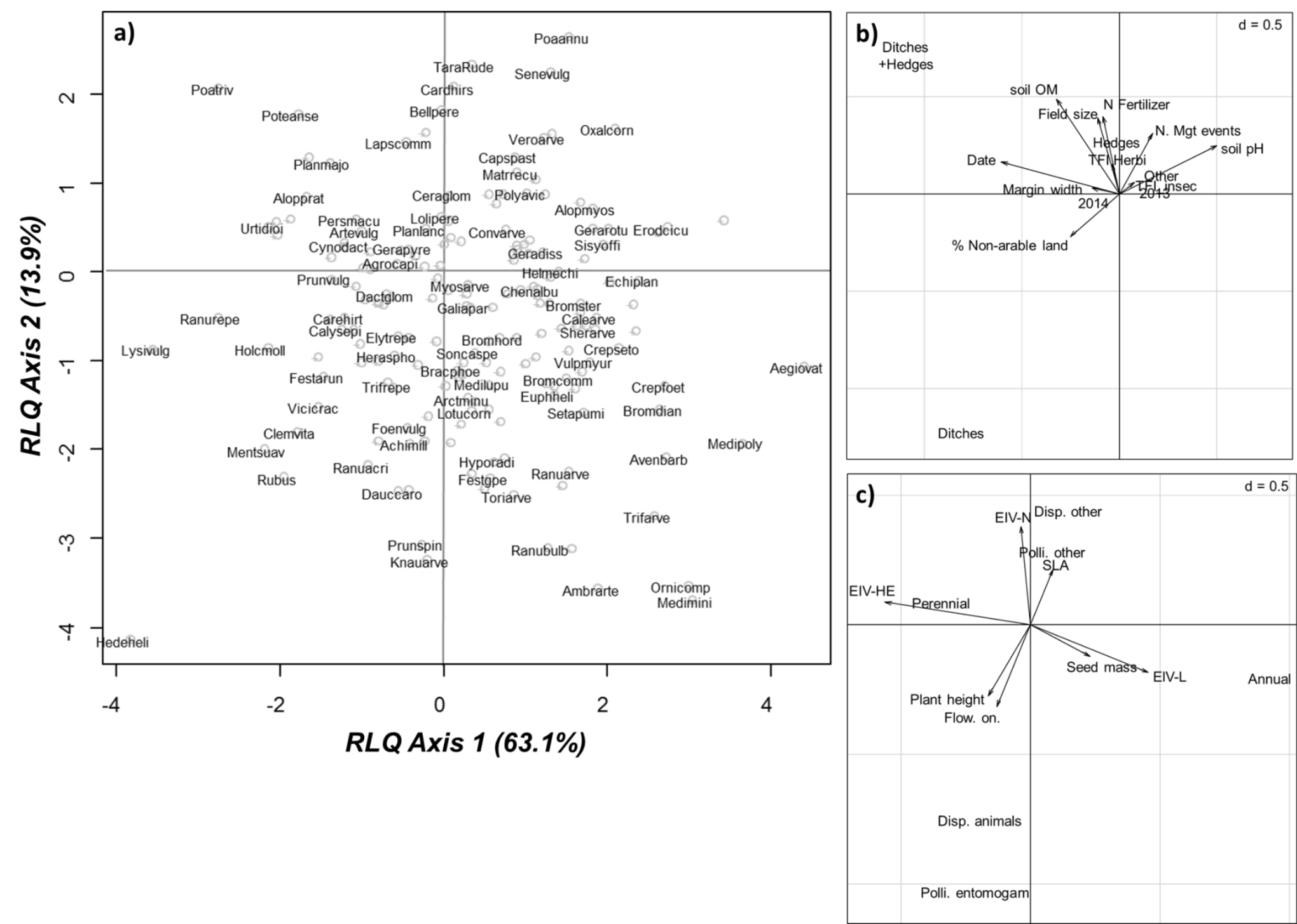
Figure 3.

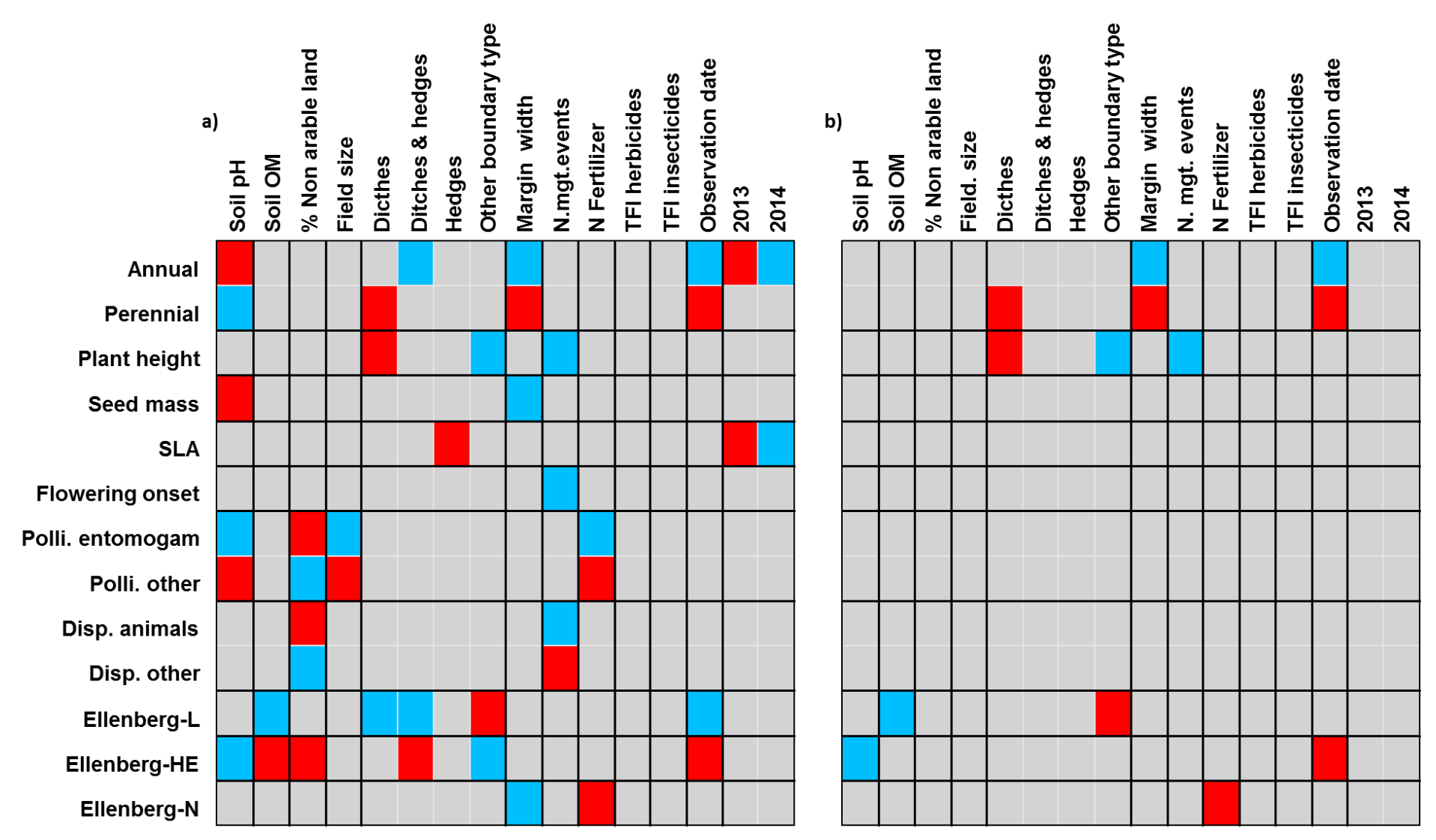


Figure 4.

\begin{tabular}{|c|c|c|c|c|c|}
\hline & AxcR1 & AxcR2 & & AxcQ1 & AxcQ2 \\
\hline Annual & & & Soil pH & & \\
\hline Perennial & & & Soil OM & & \\
\hline Plant height & & & $\%$ non-arable land & & \\
\hline Seed mass & & & Field size & & \\
\hline SLA & & & Ditches & & \\
\hline Flowering onset & & & Ditches \& hedges & & \\
\hline Polli. Entomogam & & & Hedges & & \\
\hline Polli. Other & & & Other boundary type & & \\
\hline Disp. Animals & & & Margin width & & \\
\hline Disp. Other & & & N. mgt. events & & \\
\hline Ellenberg-L & & & N Fertilizer & & \\
\hline Ellenberg-HE & & & TFI Herbicides & & \\
\hline Ellenberg- $\mathrm{N}$ & & & TFI Insecticides & & \\
\hline & & & Observation date & & \\
\hline & & & 2013 & & \\
\hline & & & 2014 & & \\
\hline
\end{tabular}


Figure 5.
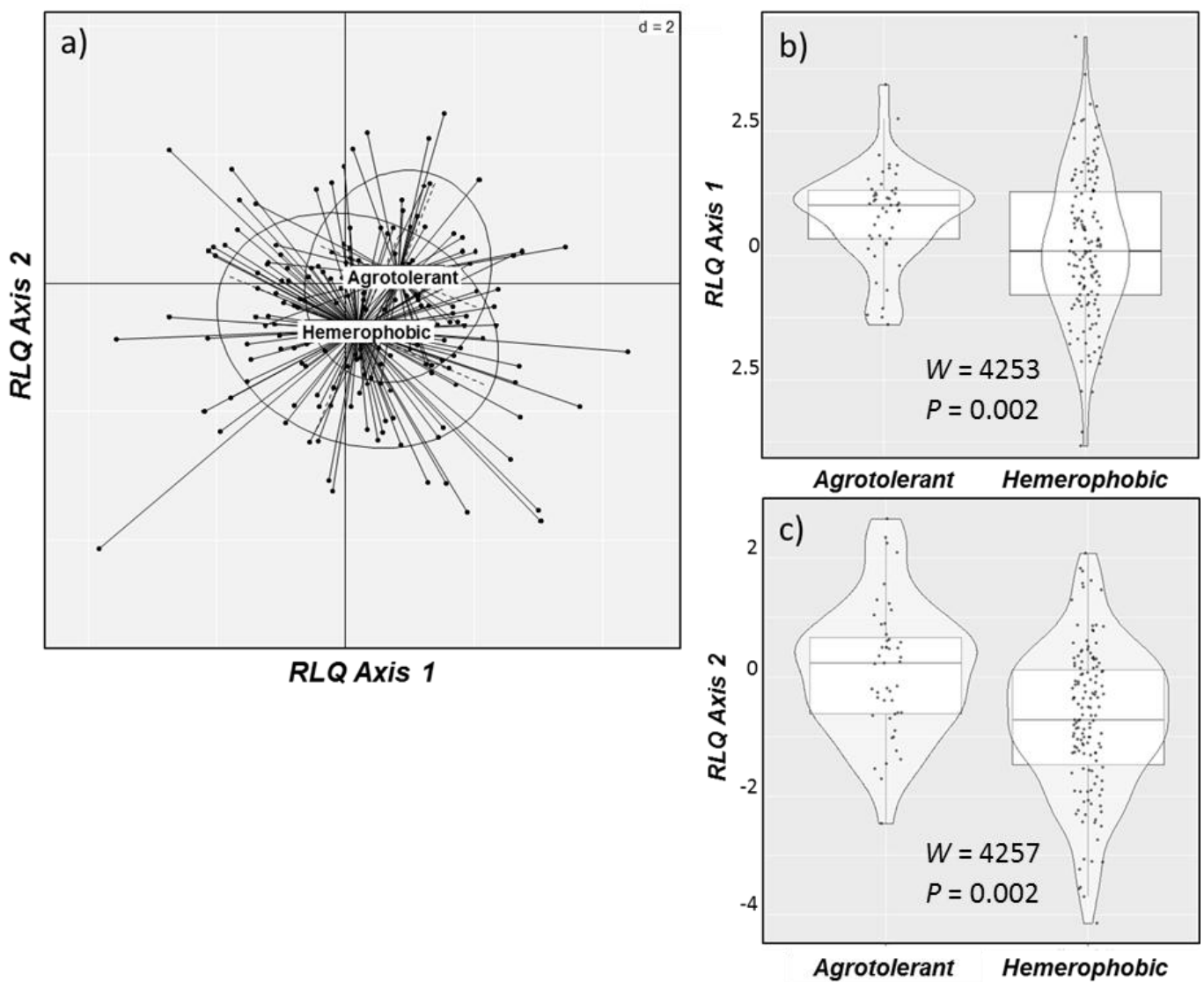
Figure 6.
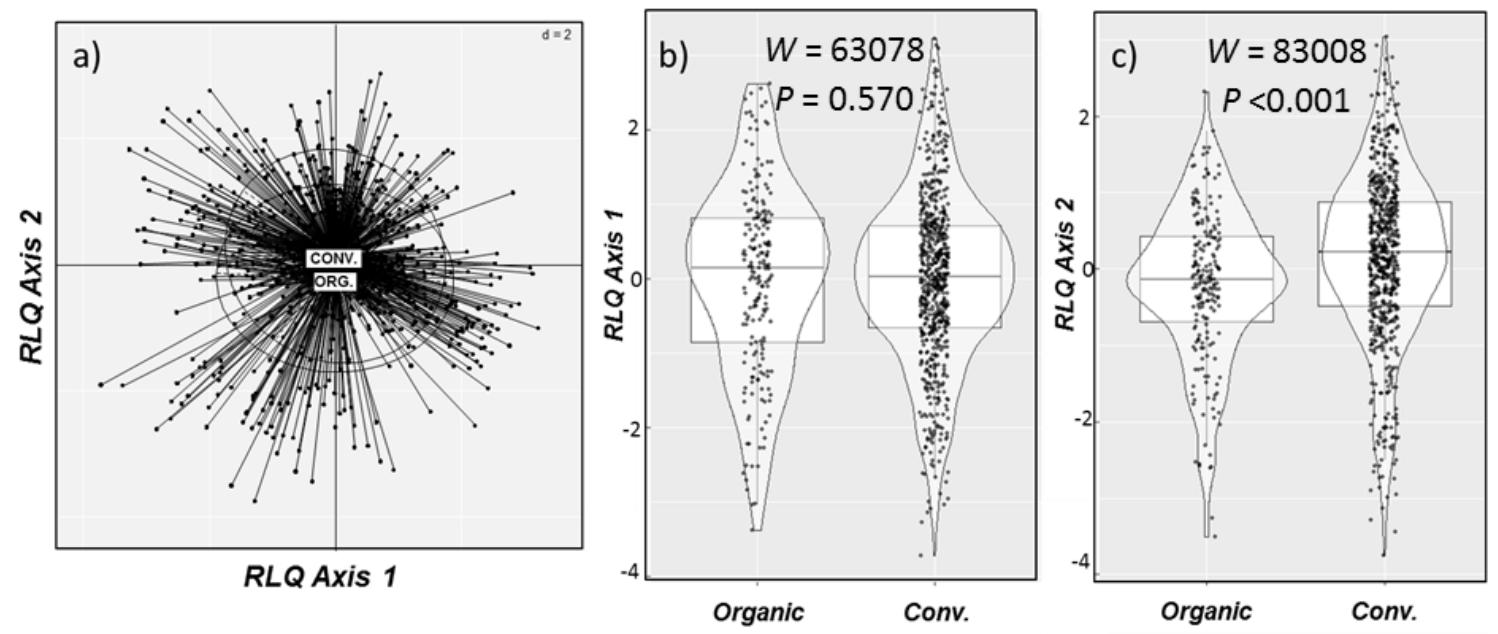
Figure 7.

a) Species richness

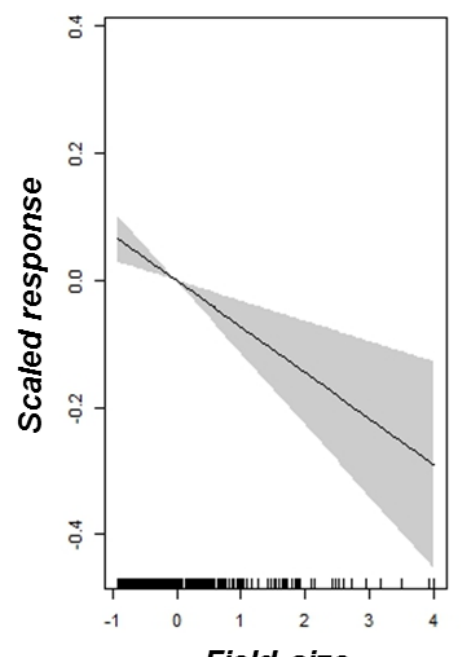

Field size
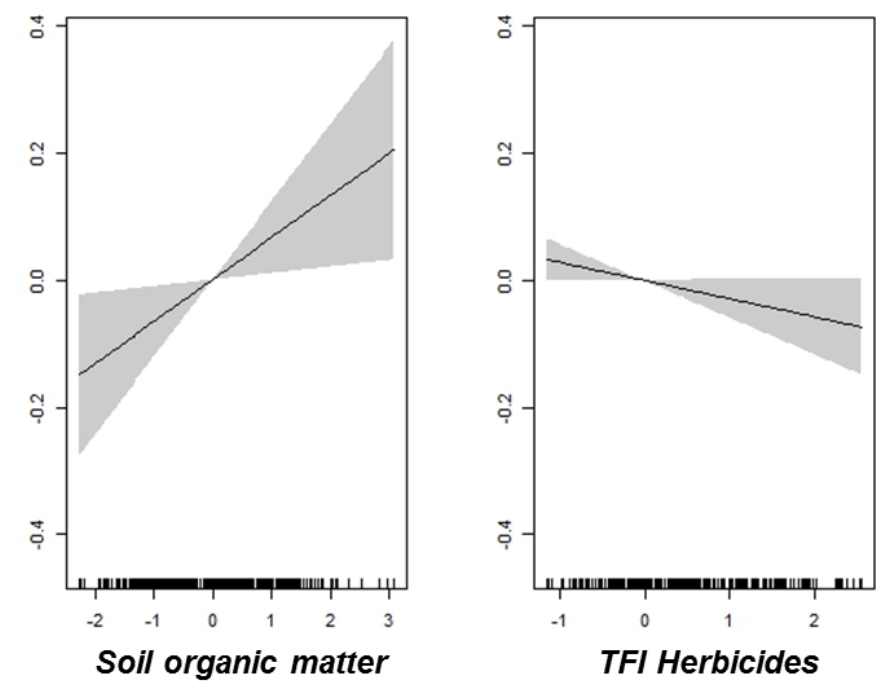

b) Functional diversity

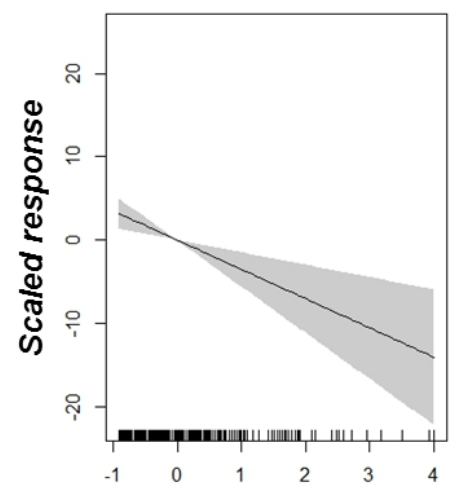

Field size

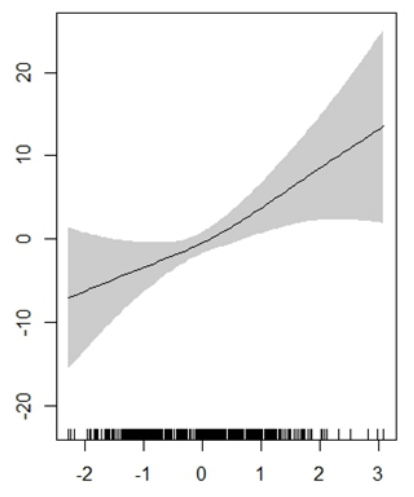

Soil organic matter

c) Relative proportion of agrotolerant/hemerophobic species
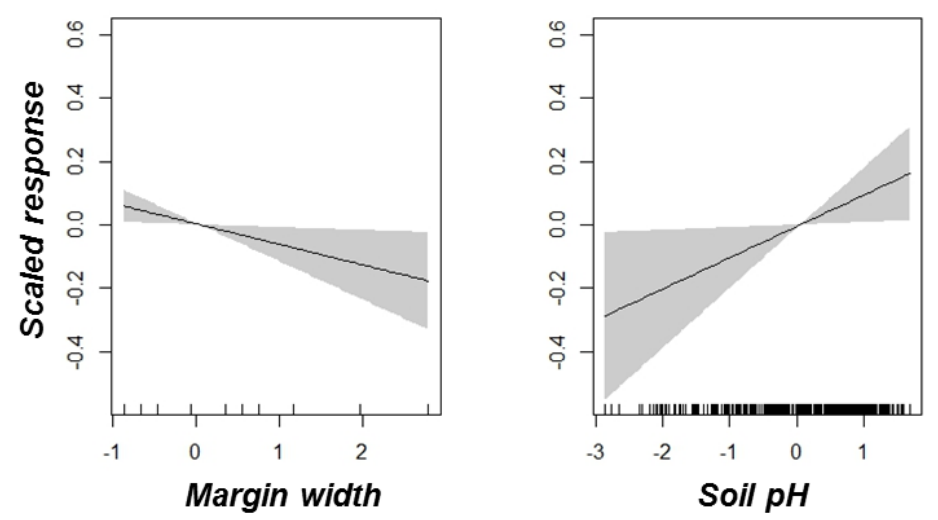